\title{
The immunoexpression of epidermal growth factor receptor in cutaneous squamous cell carcinoma
}

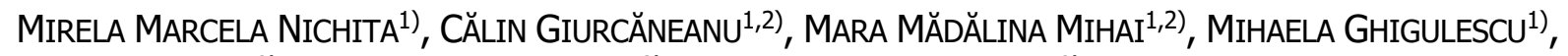

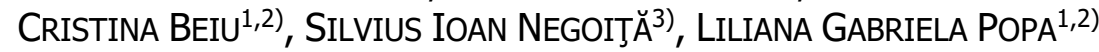 \\ 1) Department of Dermatology and Allergology, Elias Emergency University Hospital, Bucharest, Romania \\ 2) Department of Oncologic Dermatology, Elias Emergency University Hospital, Carol Davila University of Medicine and Pharmacy, \\ Bucharest, Romania \\ 3) Department of Anesthesiology and Intensive Care, Elias Emergency University Hospital, Carol Davila University of Medicine and \\ Pharmacy, Bucharest, Romania
}

\begin{abstract}
Although cutaneous squamous cell carcinomas (cSCCs) account for only $20-25 \%$ of non-melanoma skin cancers (NMSCs), they are responsible for most deaths attributable to NMSCs. Apart from SCC seric level, which increases in late-stage disease, no other predictive biomarker for CSCC exists. Epidermal growth factor receptor (EGFR) serves as a predictive biomarker and therapeutic target in numerous malignancies. EGFR immunoexpression is highly elevated in head and neck mucosal SCC. However, its immunoexpression pattern, its relationship with prognosis and survival, and the effect of EGFR targeted therapy in advanced cSCC have not been clarified. We assessed EGFR immunoexpression in 18 cases of CSCC and correlated our findings with the clinicopathological features. Immunohistochemical stainings with anti-EGFR monoclonal antibodies were practiced and the membrane and cytoplasmic immunostaining intensity and quality in the tumors and the non-lesional epithelium were analyzed. Membrane EGFR immunoexpression within the tumors increased with the tumor grade. EGFR overexpression was more frequently found in head and neck cSCCs. We did not find a direct relationship between cytoplasmic EGFR immunoexpression and clinicopathological findings and prognosis. Our results confirm that increased EGFR immunoexpression correlates with aggressive cSCC phenotypes and underline the need for novel treatments for these patients.
\end{abstract}

Keywords: epidermal growth factor receptor, squamous cell carcinoma, targeted therapy.

\section{Introduction}

Non-melanoma skin cancers (NMSCs) are the most frequent malignant tumors throughout the world [1]. They are not currently included in national cancer registries; therefore, their precise incidence is unknown, but estimated at $0.03-3.5 / 100000 / y e a r$, with the highest incidence in countries closer to the Equator [2]. Cutaneous squamous cell carcinomas (cSCCs) are second in incidence among NMSCs, accounting for $20-25 \%$ of them, markedly exceeded by basal cell carcinomas (BCCs). Nevertheless, cSCCs are responsible for most deaths caused by NMSCs and represent the leading cause of mortality attributable to skin cancer in individuals older than 75 [3]. Although prompt diagnosis and adequate treatment ensure a very good outcome in the majority of cSCC cases, a subset of aggressive cSCCs carries a poor prognosis, being characterized by significantly increased rates of recurrence and metastasis. The anatomic site (lips, ears, anogenital area), the size of the tumor $(>1.5 \mathrm{~cm}$ for tumors located on the lips or ears and $>2 \mathrm{~cm}$ for tumors located elsewhere), preexisting conditions (Marjolin's ulcer), tumor type (recurrent tumor), histological differentiation (poorly differentiated tumor), and the invasive potential (invasion of the hypodermis or deep structures, perineural or lymphatic invasion), as well as chronic immunosuppression are features that define the high-risk profile of cSCC [4-8].
Surgical excision with lateral oncological safety margins of $0.5 \mathrm{~cm}$ for low risk and $1 \mathrm{~cm}$ for high-risk tumors or Mohs micrographic surgery are the treatments of choice for cSCC. Radiotherapy is the best available alternative in patients who refuse or have contraindications for surgical treatment or in tumors that are not amenable to surgery. Chemotherapy is reserved for locally advanced or metastatic cSCCs, but resistance is frequent, with reported response rates ranging from $17 \%$ to $78 \%$ [9]. New targeted therapies, comprising epidermal growth factor receptor (EGFR) inhibitors and anti-programmed cell death protein-1 (PD-1) antibodies have been employed in such cases with promising results.

ErbB1/EGFR is a transmembrane glycoprotein that belongs to a cluster of receptor tyrosine kinases, which also includes ErbB2-4. It is activated upon binding of epidermal growth factor (EGF), transforming growth factor-alpha (TGF- $\alpha$ ), and five other related ligands (heparin-binding EGF-like growth factor, betacellulin, amphiregulin, epiregulin, and epigen). Interestingly, each ligand generates different cellular responses [10, 11]. Moreover, EGFR ligands were shown to auto- and cross-induce one another [12]. Therefore, determining the exact role of a particular ligand is a challenging and yet unfulfilled task. EGFR's signaling pathways are involved in reactive oxygen species production, cell proliferation and reduced apoptosis [13-17].

This is an open-access article distributed under the terms of a Creative Commons Attribution-NonCommercial-ShareAlike 4.0 International Public License, which permits unrestricted use, adaptation, distribution and reproduction in any medium, non-commercially, provided the new creations are licensed under identical terms as the original work and the original work is properly cited. 
High EGFR immunoexpression has been demonstrated in numerous neoplasms, including mucosal and cutaneous SCC [17] and serves as a marker of aggressive tumor behavior [18]. Patients with mucosal SCC benefit from targeted treatment with EGFR inhibitors, which block signal transduction, thus halting tumor progression [19, 20]. Several trials have investigated the effect of EGFR targeted therapy in advanced stage cSCC, but data are still scarce as the exact biology and EGFR immunoexpression pattern in these tumors have not been clarified yet.

\section{Aim}

The aims of our study were to assess EGFR immunoexpression in $\mathrm{cSCC}$, to perform a comparative analysis regarding EGFR immunoexpression in the tumor and the peritumoral epithelium, to obtain data on EGFR immunolocalization within tumoral cells and to correlate EGFR immunoexpression with demographic, clinical and histopathological (HP) parameters (age, gender, affected area, tumor size and level of invasion).

\section{a Materials and Methods}

We performed a retrospective study that included 18 cases of cSCC diagnosed in our Clinic between January 2011 and December 2015 and confirmed by HP examination. We reviewed the patients' medical records and assessed a series of parameters, including age, gender, tumor location, diameter, depth, degree of histological differentiation, perineural and lymphatic invasion, therapeutic approach, and outcome. Immunohistochemical staining using monoclonal mouse anti-human wild-type EGFR antibody, clone DAK-H1-WT was carried out on formalinfixed, paraffin-embedded tissue sections. These antibodies label the $N$-terminal part of the extracellular domain of human EGFR. The membrane and cytoplasmic immunostaining intensity and quality in both the tumor and the non-lesional epithelium were scored as absent $(0)$, faint $(1+)$, moderate $(2+)$, and intense $(3+)$.

Statistical Package for the Social Sciences (SPSS) ver. 17, STATA ver. 10 was used for statistical analyses. Categorical variables were expressed as percentages and quantitative variables as mean and standard deviation.
Quantitative variables were analyzed using Student's $t$-test or one-way analysis of variance (ANOVA) test, while the qualitative variables were tested using Pearson's $\chi^{2}$ (chi-squared) test. The linear correlations between variables were measured using Pearson's correlation coefficient.

\section{ㅁ Results}

The age of the patients included in our study ranged from 64 to 96 years, the mean age being $74.28 \pm 8.85$ years. $55.6 \%$ of patients were female patients. Most tumors (67\%) involved the head and neck region. The tumor size ranged from $0.3 \mathrm{~cm}$ to $3 \mathrm{~cm}$, with a mean value of $1.094 \pm 0.754 \mathrm{~cm}$.

On HP examination, seven (38.9\%) tumors were well differentiated, nine $(50 \%)$ were moderately differentiated and two $(11.1 \%)$ were poorly differentiated. Invasion of the deep dermis was observed in nine cases and invasion of the subjacent muscle in two cases. None of the examined tumors presented perineural, lymphatic or vascular invasion.

\section{Membrane immunostaining for EGFR within the tumor}

Membrane immunostaining for EGFR of tumor cells was observed in $16(88.9 \%)$ cases. Among these, 10 cases presented a complete membrane immunoreaction (intense in four cases, moderate in three cases and faint in three cases), and six cases an incomplete membrane immunoreaction (moderate in three cases and faint in three cases) (Figures 1-3).

Patients' gender did not influence the intensity of intratumoral membrane immunostaining for EGFR ( $p=0.520$, Fisher's exact test). The mean age was higher in patients who presented complete ( $74 \pm 10.231$ years) and incomplete (77 \pm 7.099 years) intratumoral membrane immunostaining compared with patients whose tumors did not show membrane immunostaining $(67.5 \pm 0.707$ years $)$, but the difference was not statistically significant $(p=0.443$, oneway ANOVA test).

Most tumors located in the head and neck region presented intratumoral membrane immunostaining for EGFR, which was complete in five cases and incomplete in six cases. All cSCCs located in other areas showed complete intratumoral membrane immunostaining.

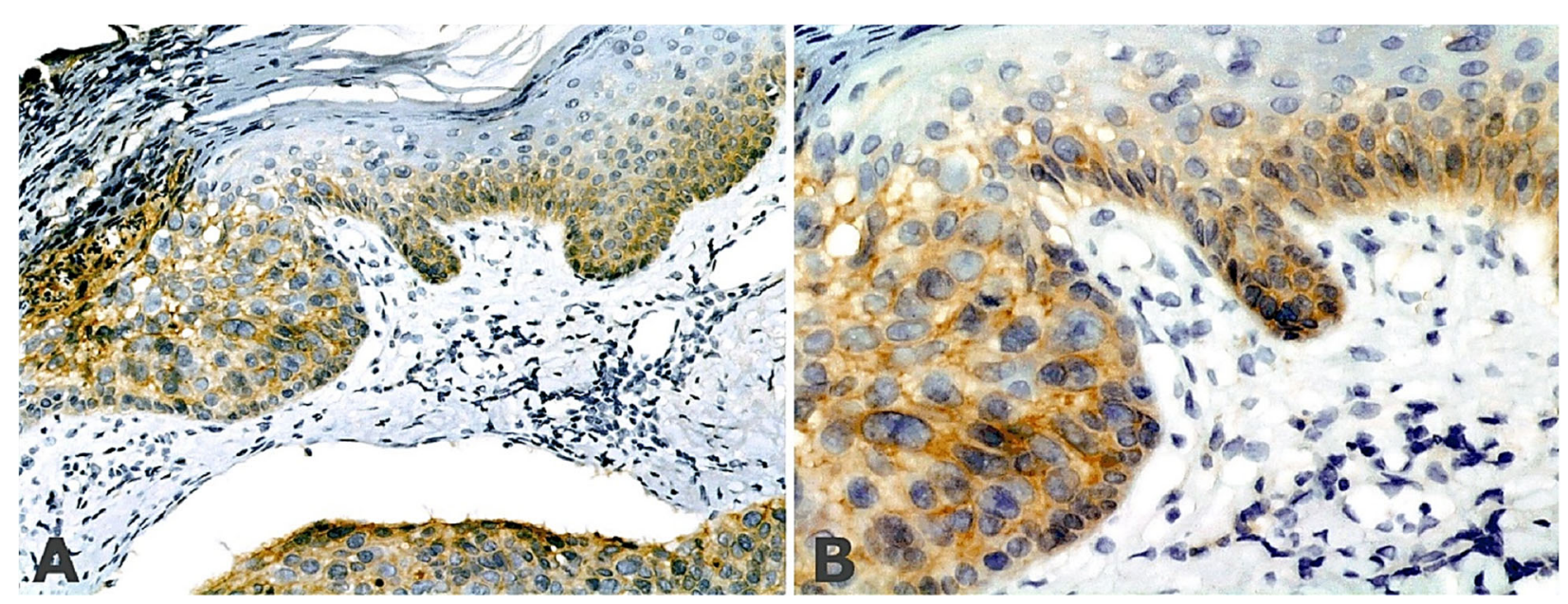

Figure 1 - (A and B) Immunohistochemical staining for EGFR in a sample of cSCC showing diffuse moderate incomplete membrane immunostaining and faint cytoplasmic immunostaining in the lower epidermis and focal immunostaining in the middle part of the epidermis. Anti-EGFR antibody immunomarking: $(A) \times 200$; (B) $\times 400$. cSCC: Cutaneous squamous cell carcinoma; EGFR: Epidermal growth factor receptor. 


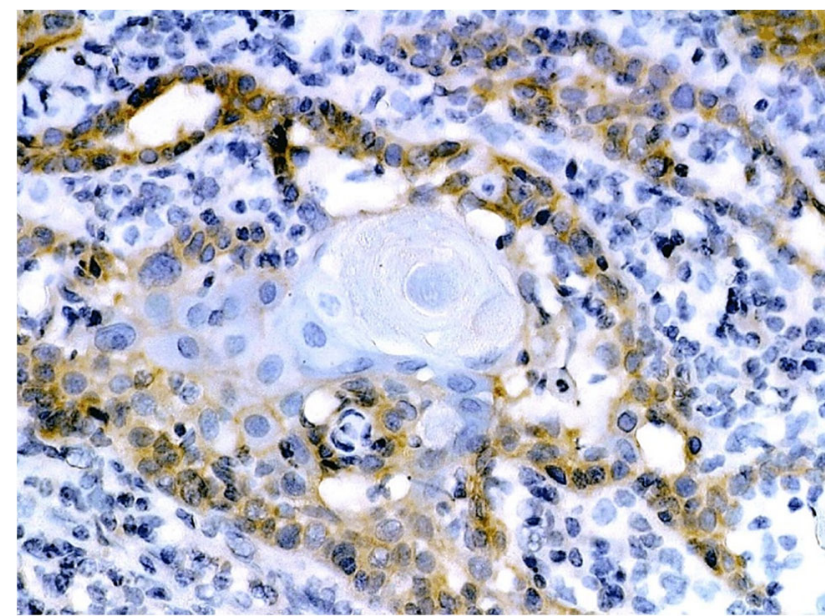

Figure 2 - Immunohistochemical staining for EGFR of a fragment of cSCC showing moderate, incomplete membrane immunostaining and focal cytoplasmic immunostaining at the periphery of the tumoral islands. Anti-EGFR antibody immunomarking, $\times 400$. cSCC: Cutaneous squamous cell carcinoma; EGFR: Epidermal growth factor receptor.

All poorly differentiated tumors presented incomplete intratumoral membrane immunostaining for EGFR. Likewise, all moderately differentiated tumors presented intratumoral membrane immunostaining, either complete $(77.8 \%)$ or incomplete $(22.2 \%)$. On the other hand, intratumoral membrane immunostaining for EGFR was absent in $28.6 \%$ of well differentiated cSCCs. Once again, the difference was not statistically significant $(p=0.055$, Fisher's exact test).

All tumors with invasion limited to the upper dermis presented incomplete intratumoral membrane immunostaining for EGFR. 88.9\% of tumors invasive in the deep dermis showed intratumoral membrane immunostaining, which was complete in $66.7 \%$ of cases and incomplete in $22.2 \%$. Both cSCCs invasive in the subjacent muscle presented intratumoral membrane immunostaining (one case with complete and one case with incomplete immunoreaction).

\section{Membrane immunostaining for EGFR in the non-lesional epithelium}

Among the 18 examined samples, membrane immunostaining for EGFR in the non-lesional epithelium was present in $15(83.3 \%)$ cases. Of these, eight cases presented complete membrane immunostaining (which was intense in two cases, moderate in two cases and faint in four cases), in six cases the immunostaining was incomplete (one case with moderate immunostaining and five cases with faint immunostaining), and one case presented a faint focal membrane immunoreaction (Figure 4).

Neither gender, nor age influenced the degree of membrane immunostaining ( $p=0.434$, Fisher's exact test and $p=0.425$, one-way ANOVA test, respectively). Nevertheless, in women, complete membrane immunostaining was most frequently encountered ( $60 \%$ of cases), while in male patients' incomplete membrane immunostaining prevailed $(37.5 \%$ of cases). The mean age was $76.38 \pm 10.028$ years for patients with complete membrane immunostaining, $75.5 \pm 8.781$ years for patients with

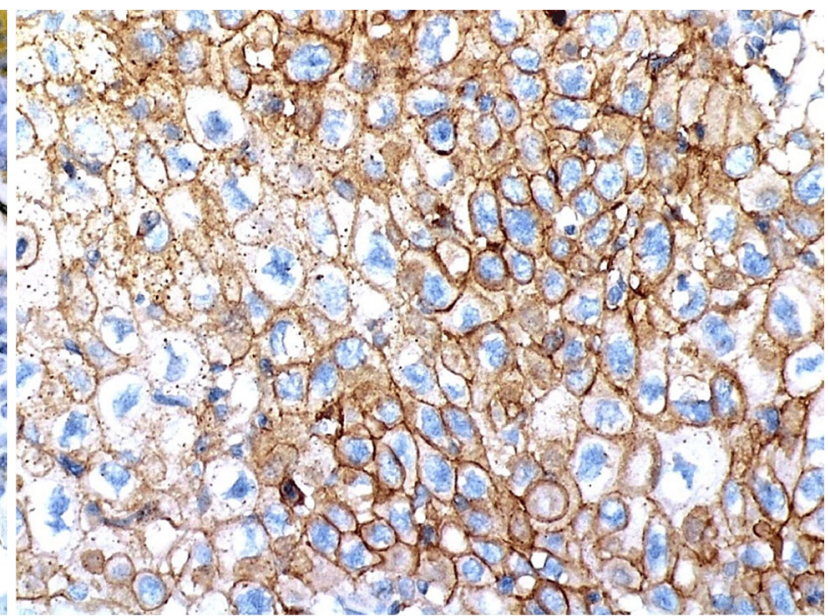

Figure 3 - Immunohistochemical staining for EGFR of a cSCC fragment showing complete, intense membrane immunostaining and faint cytoplasmic immunostaining. Anti-EGFR antibody immunomarking, $\times 400$. cSCC: Cutaneous squamous cell carcinoma; EGFR: Epidermal growth factor receptor.

incomplete membrane immunostaining, and 66.33 \pm 2.082 years for patients with no membrane immunoreaction to anti-EGFR antibodies in the non-lesional epithelium.

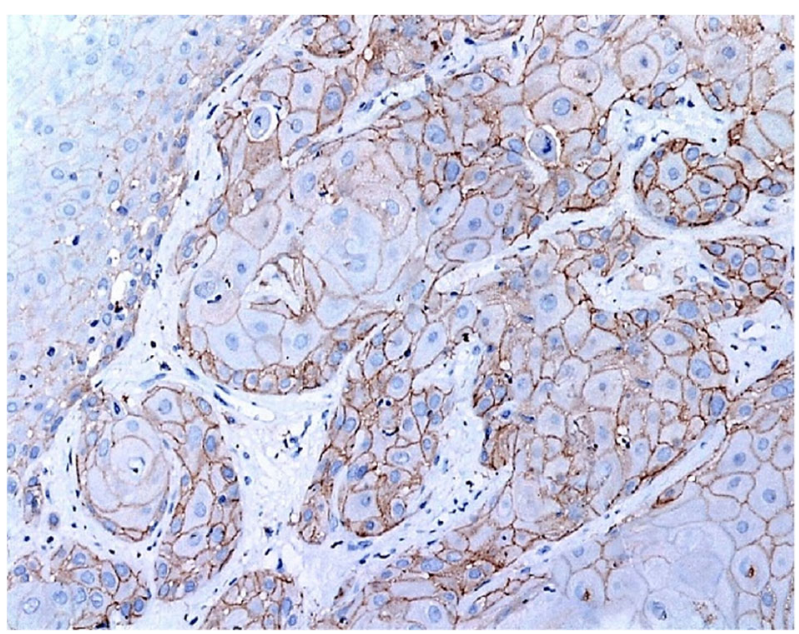

Figure 4 - Immunohistochemical staining for EGFR of a cSCC fragment showing complete, intense membrane immunostaining especially in the periphery of the tumor and complete, faint membrane immunostaining in the peritumoral epithelium. Anti-EGFR antibody immunomarking, $\times 200$. cSCC: Cutaneous squamous cell carcinoma; EGFR: Epidermal growth factor receptor.

Six $(50 \%)$ cases of cSCC located in the head and neck region presented incomplete membrane immunostaining for EGFR in the non-lesional epithelium and three (25\%) cases presented complete membrane immunostaining. cSCCs located in other areas presented complete membrane immunoreaction in the non-lesional epithelium.

The degree of histological differentiation did not significantly influence the intensity of membrane immunostaining for EGFR in the non-lesional epithelium $(p=0.771$, Fisher's exact test). All poorly differentiated tumors presented membrane immunostaining in the non-lesional epithelium (one case with complete and one case with incomplete membrane immunostaining). Membrane 
immunoreaction in the non-lesional epithelium was observed in the majority $(88.89 \%)$ of moderately differentiated tumors (four cases with complete and four cases with incomplete membrane immunostaining). Among the well differentiated cSCCs in our study, three (42.9\%) presented complete membrane immunostaining, one (14.3\%) presented incomplete membrane immunostaining, and one $(14.3 \%)$ presented focal membrane immunostaining for EGFR.

Membrane immunostaining for EGFR in the nonlesional epithelium was observed in all cases with invasion of the subjacent muscle (one case with complete and one case with incomplete membrane immunostaining) and in most tumors invasive in the deep dermis [five $(55.6 \%)$ cases with complete and two $(22.2 \%)$ cases with incomplete membrane immunoreaction]. Incomplete membrane immunostaining was present in cases of cSCC limited to the superficial dermis. Once again, the differences did not prove statistically significant ( $p=0.469$, Fisher's exact test).

\section{Cytoplasmic immunostaining for EGFR within the tumor}

Intratumoral cytoplasmic immunostaining for EGFR was observed in five cases, three cases of which presented diffuse cytoplasmic immunostaining (one case with moderate and two cases with faint immunoreaction) and two cases with focal cytoplasmic immunostaining (Figures 5 and 6).

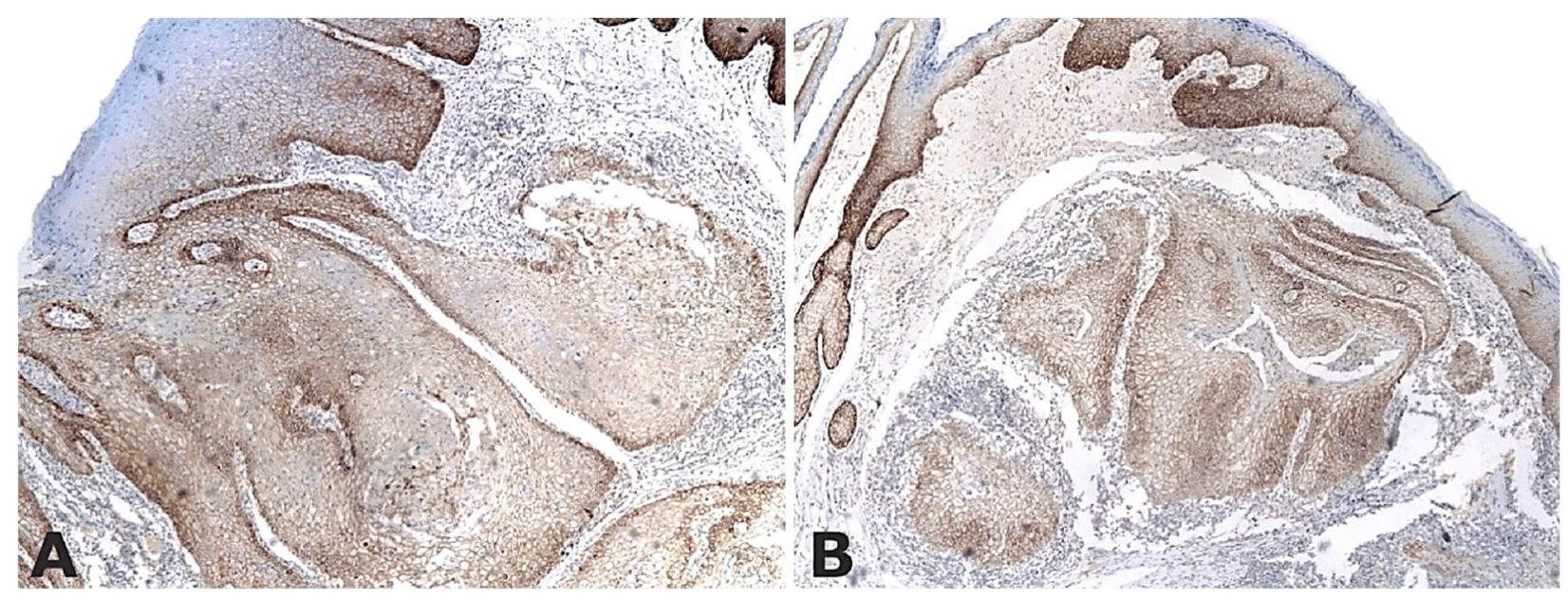

Figure 5 - (A and B) Immunohistochemical staining for EGFR of a skin fragment presenting cSCC with intense, complete membrane immunostaining and diffuse, moderate cytoplasmic immunostaining in both the center (A) and the periphery (B) of the tumor. Anti-EGFR antibody immunomarking: (A and B) $\times 50$. cSCC: Cutaneous squamous cell carcinoma; EGFR: Epidermal growth factor receptor.

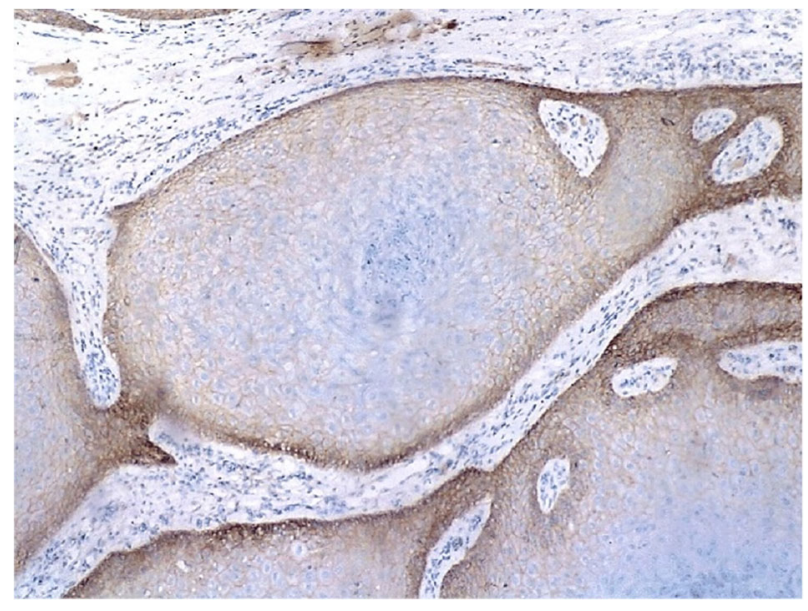

Figure 6 - Immunohistochemical staining for EGFR of a cSCC fragment showing complete, moderate immunostaining in the periphery of the tumor. Anti-EGFR antibody immunomarking, $\times 100$. cSCC: Cutaneous squamous cell carcinoma; EGFR: Epidermal growth factor receptor.

The intensity of the intratumoral cytoplasmic immunostaining for EGFR was not influenced by the patients' gender or age $(p=1.0$, Fisher's exact test and $p=0.779$, one-way ANOVA test, respectively). The mean age was $70.5 \pm 4.95$ years for patients with tumors that showed diffuse cytoplasmic immunostaining, $74 \pm 9.539$ years for patients with tumors in which the cytoplasmic immuno- staining was focal, and $75.58 \pm 9.643$ years for patients with tumors that did not present cytoplasmic immunostaining.

Regarding the location of tumors, only $25 \%$ of cSCCs situated in the head and neck region and one cSCC situated on the upper limb presented intratumoral cytoplasmic immunostaining for EGFR.

Focal intratumoral cytoplasmic immunostaining for EGFR was only observed in well differentiated tumors $(50 \%)$, while diffuse cytoplasmic immunostaining was noticed in $11.1 \%$ of moderately differentiated and $50 \%$ of poorly differentiated cSCCs. The differences were statistically significant ( $p=0.043$, Fisher's exact test).

Diffuse cytoplasmic immunostaining for EGFR was present in half of the cases with muscular invasion and invasion of the upper dermis. $50 \%$ of cases invasive in the upper dermis and $25 \%$ of cases invasive in the deep dermis presented focal cytoplasmic immunostaining. All other tumors did not present cytoplasmic immunoreaction. The differences were not statistically significant $(p=0.152$, Fisher's exact test).

Cytoplasmic immunostaining for EGFR in the non-lesional epithelium

Cytoplasmic immunostaining for EGFR in the nonlesional epithelium was observed in five $(27.8 \%)$ cases. Among these, one case presented diffuse immunostaining and four cases presented focal immunostaining (Table 1). 
Table 1 - EGFR immunoexpression in the tumors and non-lesional epithelium

\begin{tabular}{|c|c|c|c|c|}
\hline $\begin{array}{c}\text { Case } \\
\text { No. }\end{array}$ & Location & $\begin{array}{c}\text { Membrane immunostaining } \\
\text { intensity }\end{array}$ & $\begin{array}{c}\text { Cytoplasmic } \\
\text { immunostaining intensity }\end{array}$ & Details \\
\hline \multirow{2}{*}{1.} & Tumor & $\begin{array}{l}\text { Complete, intense, both in the center } \\
\text { and the periphery of the tumor }\end{array}$ & $\begin{array}{l}\text { Moderate, diffuse and } \\
\text { focal granular, intense }\end{array}$ & $\begin{array}{c}\text { Fine and coarse } \\
\text { granules }\end{array}$ \\
\hline & Non-lesional epithelium & $\begin{array}{c}\text { Complete, intense, in the lower } 2 / 3 \\
\text { of the epidermis }\end{array}$ & $\begin{array}{l}\text { Moderate, granular, } \\
\text { focal }\end{array}$ & - \\
\hline \multirow{2}{*}{2.} & Tumor & Quasi-complete, intense & Absent & $\begin{array}{l}\text { No reaction in the } \\
\text { center of the tumor }\end{array}$ \\
\hline & Non-lesional epithelium & $\begin{array}{l}\text { Quasi-complete, intense, in the lower } 1 / 3 \\
\text { of the epidermis and in the hair follicles }\end{array}$ & Absent & - \\
\hline \multirow{2}{*}{3.} & Tumor & Quasi-complete, faint & Absent & $\begin{array}{l}\text { No reaction in the } \\
\text { center of the tumor }\end{array}$ \\
\hline & Non-lesional epithelium & $\begin{array}{l}\text { Quasi-complete, faint in the lower } 2 / 3 \\
\text { of the epidermis }\end{array}$ & $\begin{array}{l}\text { Diffuse, faint, in the lower } \\
1 / 3 \text { of the epidermis }\end{array}$ & - \\
\hline \multirow[t]{2}{*}{4.} & Tumor & Complete, faint & $\begin{array}{l}\text { Faint, diffuse in the } \\
\text { periphery of the tumor }\end{array}$ & $\begin{array}{l}\text { Very faint membrane } \\
\text { staining in the center } \\
\text { of the tumor }\end{array}$ \\
\hline & Non-lesional epithelium & Complete, faint in the $2 / 3$ lower epidermis & $\begin{array}{l}\text { Diffuse in the lower } 1 / 3 \\
\text { of the epidermis }\end{array}$ & - \\
\hline \multirow{2}{*}{5.} & Tumor & Complete, moderate, diffuse & Absent & - \\
\hline & Non-lesional epithelium & Complete, faint throughout the epidermis & Absent & - \\
\hline \multirow[t]{2}{*}{6.} & Tumor & Complete, faint & Absent & $\begin{array}{l}\text { No reaction in the } \\
\text { center of the tumor }\end{array}$ \\
\hline & Non-lesional epithelium & Absent & Absent & - \\
\hline \multirow{2}{*}{7.} & Tumor & Complete, moderate & $\begin{array}{l}\text { Focal, moderate, finely } \\
\text { granular }\end{array}$ & $\begin{array}{l}\text { No reaction in the } \\
\text { center of the tumor }\end{array}$ \\
\hline & Non-lesional epithelium & $\begin{array}{l}\text { Complete, faint in the lower } 1 / 3 \\
\text { of the epidermis }\end{array}$ & Absent & - \\
\hline \multirow{2}{*}{8.} & Tumor & Absent & Absent & - \\
\hline & Non-lesional epithelium & Absent & Focal, faint, finely granular & - \\
\hline \multirow[b]{2}{*}{9.} & Tumor & Quasi-complete, faint, diffuse & Absent & - \\
\hline & Non-lesional epithelium & $\begin{array}{l}\text { Incomplete, faint, focal in the lower } 1 / 3 \\
\text { of the epidermis }\end{array}$ & Absent & - \\
\hline \multirow[b]{2}{*}{10.} & Tumor & Incomplete, faint & Absent & $\begin{array}{l}\text { No reaction in the } \\
\text { center of the tumor }\end{array}$ \\
\hline & Non-lesional epithelium & $\begin{array}{l}\text { Incomplete, faint in the lower } 1 / 3 \text { of the } \\
\text { epidermis and complete, intense in the } \\
\text { hair follicles }\end{array}$ & Focal, faint & - \\
\hline \multirow{2}{*}{11.} & Tumor & Complete, moderate & Absent & $\begin{array}{l}\text { No reaction in the } \\
\text { center of the tumor }\end{array}$ \\
\hline & Non-lesional epithelium & $\begin{array}{l}\text { Incomplete, faint in the lower } 1 / 3 \\
\text { of the epidermis }\end{array}$ & Absent & - \\
\hline \multirow{2}{*}{12.} & Tumor & Incomplete, moderate & focal & $\begin{array}{l}\text { No reaction in the } \\
\text { center of the tumor }\end{array}$ \\
\hline & Non-lesional epithelium & $\begin{array}{l}\text { Incomplete, faint in the lower } 1 / 3 \\
\text { of the epidermis }\end{array}$ & Absent & - \\
\hline \multirow{2}{*}{13.} & Tumor & Absent & Absent & - \\
\hline & Non-lesional epithelium & Absent & Absent & - \\
\hline \multirow[b]{2}{*}{14.} & Tumor & Incomplete, moderate, diffuse & Diffuse, faint & - \\
\hline & Non-lesional epithelium & $\begin{array}{l}\text { Incomplete, faint in the lower } 2 / 3 \\
\text { of the epidermis }\end{array}$ & Absent & - \\
\hline \multirow[b]{2}{*}{15.} & Tumor & Incomplete, faint, diffuse & Absent & - \\
\hline & Non-lesional epithelium & $\begin{array}{l}\text { Incomplete, moderate in the lower } 1 / 3 \text { of the } \\
\text { epidermis and focal in the middle epidermis }\end{array}$ & Absent & - \\
\hline \multirow{2}{*}{16.} & Tumor & Incomplete, moderate & Absent & $\begin{array}{l}\text { No reaction in the } \\
\text { center of the tumor }\end{array}$ \\
\hline & Non-lesional epithelium & Focal, faint in the lower $2 / 3$ of the epidermis & $\begin{array}{c}\text { Faint, in the lower } 1 / 3 \\
\text { of the epidermis }\end{array}$ & - \\
\hline \multirow{2}{*}{17.} & Tumor & $\begin{array}{l}\text { Complete, intense at the periphery of the } \\
\text { tumor and complete, faint in the center }\end{array}$ & Absent & - \\
\hline & Non-lesional epithelium & $\begin{array}{l}\text { Complete, moderate in the lower } 1 / 3 \\
\text { of the epidermis }\end{array}$ & Absent & - \\
\hline \multirow{2}{*}{18.} & Tumor & Faint, at the periphery of the tumor & Absent & $\begin{array}{l}\text { No reaction in the } \\
\text { center of the tumor }\end{array}$ \\
\hline & Non-lesional epithelium & $\begin{array}{c}\text { Complete, faint in the lower } 1 / 3 \\
\text { of the epidermis }\end{array}$ & Absent & - \\
\hline
\end{tabular}

Cytoplasmic immunoreaction in the non-lesional epithelium was observed in $10 \%$ of cases that affected female patients (diffuse cytoplasmic immunostaining) and in $50 \%$ of male patients (focal cytoplasmic immunostaining) ( $p=0.023$, Fisher's exact test).

The intensity of the cytoplasmic immunostaining for 
EGFR in the non-lesional epithelium did not vary significantly between age groups $(p=0.586$, one-way ANOVA test). The mean age was lower for patients with diffuse cytoplasmic immunostaining in the non-lesional epithelium (65 years) compared with that of patients with focal cytoplasmic immunostaining in the non-lesional epithelium ( $74.5 \pm 10.149$ years) and with patients with no cytoplasmic immunoreaction in the perilesional epithelium (74.92 \pm 8.808 years).

Only tumors located in the head and neck region presented focal peritumoral cytoplasmic immunostaining for EGFR (25\%).

None of the poorly differentiated cSCCs presented peritumoral cytoplasmic immunostaining for EGFR. Focal peritumoral cytoplasmic immunostaining was observed in $22.2 \%$ of moderately differentiated tumors and $33.3 \%$ of well differentiated tumors. One (16.67\%) well differentiated tumor presented diffuse cytoplasmic immunostaining in the non-lesional epithelium.

None of the tumors that only invaded the superficial dermis showed peritumoral cytoplasmic immunostaining for EGFR, whereas all tumors invasive in the subjacent muscle presented focal peritumoral cytoplasmic immunostaining and one $(11.1 \%)$ case of cSCC invasive in the deep dermis presented diffuse cytoplasmic immunostaining in the non-tumoral epithelium.

\section{ㅁ Discussions}

cSCCs are easily cured if diagnosed and treated early. The metastatic potential of $\mathrm{cSCC}$ is low, reported rates varying between $1.9 \%$ and $2.6 \%$ [21]. However, a subgroup of high-risk cSCC portend greater morbidity and significantly higher mortality due to their aggressive nature and lack of efficient, standardized treatments [22, 23]. Apart from the seric level of SCC, which only increases in latestage disease [24], no other predictive biomarkers are available at the moment for cSCC. EGFR level could serve as one as overexpression of EGFR has been shown to promote the progression of carcinomas, sarcomas, nonsmall cell lung cancer (NSCLC), and malignant gliomas [25]. Tumor grade, recurrence risk, metastasis risk and prognosis can all be predicted by measuring the EGFR level $[25,26]$. Although EGFR immunoexpression has been demonstrated to be highly elevated in head and neck mucosal SCC [27, 28], its level of immunoexpression in cSCC and its relationship with prognosis and survival has been little investigated.

In our study, gender, age, and tumor location did not significantly influence the intensity of membrane immunostaining for EGFR inside the tumor and in the peritumoral epithelium. Most of the studied samples presented membrane immunostaining for EGFR in tumor cells (88.9\%), similar to previous research that found EGFR immunoexpression in $88-100 \%$ of cSCCs [29-32]. Regarding the correlation between EGFR immunoexpression and the degree of histological differentiation, we noticed that all poorly differentiated tumors presented both tumoral and peritumoral membrane immunostaining for EGFR. Likewise, all moderately differentiated tumors presented tumoral membrane immunostaining for EGFR and $90 \%$ of them also presented membrane immunostaining in the peritumoral epithelium. By contrast, in almost a third of well differentiated cSCCs, membrane immunostaining for EGFR was absent within tumor cells. The intensity of membrane immunostaining for EGFR varied with the depth of invasion of cSCCs. Complete membrane immunostaining was observed in tumors invasive in the deep dermis and subjacent muscle, but not in tumors limited to the superficial dermis. In conformity with the results of previous studies [33], our findings suggest that EGFR immunoexpression in the membrane of tumor cells increases with the tumor grade.

Only five of our cases presented cytoplasmic immunostaining for EGFR in tumor cells. Diffuse cytoplasmic immunostaining of tumor cells was only observed in moderately or poorly differentiated tumors, whereas well differentiated tumors presented focal cytoplasmic immunostaining. Similar to the membrane immunostaining for EGFR, cytoplasmic immunostaining was not significantly influenced by patients' gender or age. Tumor location, on the other hand, was an important factor as three of the five tumors that presented cytoplasmic immunostaining were located in the head and neck region. Moreover, only cSCCs with this location presented peritumoral cytoplasmic immunostaining for EGFR ( $25 \%$ of cases). These data are in accordance with the results of other studies, which showed that increased EGFR immunoexpression was more frequently found in head and neck primary cSCCs that progressed [32]. The intensity and quality of the cytoplasmic immunostaining for EGFR did not vary in relation to the depth of tumor invasion. Thus, a small number of samples in our study presented cytoplasmic immunostaining for EGFR regardless of the degree of histological differentiation and depth of invasion. Although other studies concluded that tumoral cytoplasmic immunostaining for EGFR correlates with a poor prognosis in cSCC [34], our results do not support this hypothesis. Similar to our results, Sweeny et al. did not find a direct relationship between cytoplasmic EGFR immunoexpression and clinicopathological findings and prognosis [29].

Recurrent or locally advanced cSCC needs to be treated aggressively, both surgically and with adjuvant radiation. In cases that are not amenable for extensive surgery or do not respond to standard treatments and in the setting of metastatic cSCC, therapeutic options are few and response rates to conventional chemotherapy vary greatly [9]. EGFR inhibitors, in the form of monoclonal antibodies (Cetuximab, Panitumumab) or tyrosine kinase inhibitors (Erlotinib, Gefitinib, Lapatinib) are currently used for the treatment of NSCLC, metastatic colorectal cancer, head and neck, pancreatic and breast cancer, either as monotherapy or combined with chemo- or radiotherapy [25] and ongoing clinical trials assess the efficacy of EGFR antagonists in anaplastic thyroid cancer. The utility of anti-EGFR targeted therapies in advanced cSCC has also been investigated, but the trials carried out so far have yielded conflicting results. Disease control was achieved in $28-69 \%$ of patients with advanced cSCC treated with anti-EGFR monoclonal antibodies [35, 36], while treatment with tyrosine kinase inhibitors was associated with modest results $(10 \%$ response rate for Erlotinib and $16 \%$ for Gefitinib) [37, 38]. The use of EGFR antagonists as neoadjuvant therapy is also appealing as they have been proven to possess radio- and chemosensitizing potential and to increase the likelihood of complete tumor resection when administered preoperatively [39], thus diminishing the risk of complications associated 
with recurrent cancer surgery [40-42]. EGFR inhibitors are generally well tolerated, with skin toxicity being the most common adverse effect [43, 44]. An important drawback of anti-EGFR therapy is the limited duration of the response. Further studies should address not only the efficacy of such treatments in $\mathrm{cSCC}$, but also the identification of novel predictive markers of response and prognosis. Other future perspectives are represented by nanotechnology-derived delivery systems for EGFR inhibitors that enhance their pharmacokinetic profile [45].

\section{Conclusions}

Overexpression of EGFR correlates with more aggressive phenotypes of cSCC, with a higher recurrence risk and an increased metastatic potential. In the absence of other reliable prognostic tools, EGFR could serve as a predictive biomarker. Moreover, EGFR inhibitors are currently one of the very few available treatment options for patients with advanced, unresectable cSCC apart from conventional cytotoxic and radiation therapy.

\section{Conflict of interests}

The authors declare that they have no conflict of interests.

\section{Compliance with ethical standards}

We obtained the approval of the Ethics Committee of Elias Emergency University Hospital, Bucharest, Romania, for the publication of this manuscript.

\section{Consent}

Written informed consents were obtained from the patients included in the study for the publication of the results and accompanying images.

\section{References}

[1] Stern RS. Prevalence of a history of skin cancer in 2007: results of an incidence-based model. Arch Dermatol, 2010, 146(3):279-282. https://doi.org/10.1001/archdermatol.2010.4 PMID: 20231498

[2] Najjar T. Cutaneous squamous cell carcinoma. Medscape, updated: July 8, 2020; accessed: September 25, 2020. http:// emedicine.medscape.com/article/1965430-overview\#a1

[3] Burton KA, Ashack KA, Khachemoune A. Cutaneous squamous cell carcinoma: a review of high-risk and metastatic disease. Am J Clin Dermatol, 2016, 17(5):491-508. https://doi.org/10. 1007/s40257-016-0207-3 PMID: 27358187

[4] Skulsky SL, O'Sullivan B, McArdle O, Leader M, Roche M, Conlon PJ, O'Neill JP. Review of high-risk features of cutaneous squamous cell carcinoma and discrepancies between the American Joint Committee on Cancer and NCCN Clinical Practice Guidelines in Oncology. Head Neck, 2017, 39(3) 578-594. https://doi.org/10.1002/hed.24580 PMID: 27882625

[5] Housman TS, Feldman SR, Williford PM, Fleischer AB Jr, Goldman ND, Acostamadiedo JM, Chen GJ. Skin cancer is among the most costly of all cancers to treat for the Medicare population. J Am Acad Dermatol, 2003, 48(3):425-429. https:// doi.org/10.1067/mjd.2003.186 PMID: 12637924

[6] Parekh V, Seykora JT. Cutaneous squamous cell carcinoma. Clin Lab Med, 2017, 37(3):503-525. https://doi.org/10.1016/ j.cll.2017.06.003 PMID: 28802498

[7] Clayman GL, Lee JJ, Holsinger FC, Zhou X, Duvic M, ElNaggar AK, Prieto VG, Altamirano E, Tucker SL, Strom SS, Kripke ML, Lippman SM. Mortality risk from squamous cell skin cancer. J Clin Oncol, 2005, 23(4):759-765. https://doi. org/10.1200/JCO.2005.02.155 PMID: 15681519

[8] Manyam BV, Gastman B, Zhang AY, Reddy CA, Burkey BB, Scharpf J, Alam DS, Fritz MA, Vidimos AT, Koyfman SA. Inferior outcomes in immunosuppressed patients with highrisk cutaneous squamous cell carcinoma of the head and neck treated with surgery and radiation therapy. J Am Acad Dermatol, 2015, 73(2):221-227. https://doi.org/10.1016/j.jaad. 2015.04.037 PMID: 26028524

[9] Cranmer LD, Engelhardt C, Morgan SS. Treatment of unresectable and metastatic cutaneous squamous cell carcinoma. Oncologist, 2010, 15(12):1320-1328. https://doi.org/10.1634/ theoncologist.2009-0210 PMID: 21147868 PMCID: PMC 3227927

[10] Knudsen SLJ, Mac ASW, Henriksen L, van Deurs B, Grøvdal LM. EGFR signaling patterns are regulated by its different ligands. Growth Factors, 2014, 32(5):155-163. https://doi.org/10.3109/ 08977194.2014.952410 PMID: 25257250

[11] Ronan T, Macdonald-Obermann JL, Huelsmann L, Bessman NJ, Naegle KM, Pike LJ. Different epidermal growth factor receptor (EGFR) agonists produce unique signatures for the recruitment of downstream signaling proteins. J Biol Chem, 2016, 291(11): 5528-5540. https://doi.org/10.1074/jbc.M115.710087 PMID: 26786109 PMCID: PMC4786695

[12] Barnard JA, Graves-Deal R, Pittelkow MR, DuBois R, Cook P, Ramsey GW, Bishop PR, Damstrup L, Coffey RJ. Auto- and cross-induction within the mammalian epidermal growth factorrelated peptide family. J Biol Chem, 1994, 269(36):2281722822. PMID: 8077234

[13] Sirokmány G, Pató A, Zana M, Donkó Á, Bíró A, Nagy P, Geiszt M. Epidermal growth factor-induced hydrogen peroxide production is mediated by dual oxidase 1. Free Radic Biol Med, 2016, 97:204-211. https://doi.org/10.1016/j.freeradbiomed. 2016.05.028 PMID: 27262981

[14] Horn L, Lovly C. Update on HER1-3 in advanced non-smallcell lung cancer. J Thorac Oncol, 2012, 7(16 Suppl 5):S369S371. https://doi.org/10.1097/JTO.0b013e31826defaa PMID: 23160321

[15] Hong L, Han Y, Brain L. The role of epidermal growth factor receptor in prognosis and treatment of gastric cancer. Expert Rev Gastroenterol Hepatol, 2014, 8(1):111-117. https://doi.org/ 10.1586/17474124.2014.844648 PMID: 24410474

[16] Cohen RB. Current challenges and clinical investigations of epidermal growth factor receptor (EGFR)- and ErbB familytargeted agents in the treatment of head and neck squamous cell carcinoma (HNSCC). Cancer Treat Rev, 2014, 40(4): 567-577. https://doi.org/10.1016/j.ctrv.2013.10.002 PMID: 24216225

[17] Uribe P, Gonzalez S. Epidermal growth factor receptor (EGFR) and squamous cell carcinoma of the skin: molecular bases for EGFR-targeted therapy. Pathol Res Pract, 2011, 207(6): 337-342. https://doi.org/10.1016/j.prp.2011.03.002 PMID: 21531084

[18] Veness MJ. Treatment recommendations in patients diagnosed with high-risk cutaneous squamous cell carcinoma. Australas Radiol, 2005, 49(5):365-376. https://doi.org/10.1111/j.14401673.2005.01496.x PMID: 16174174

[19] Baselga J. The EGFR as a target for anticancer therapy focus on Cetuximab. Eur J Cancer, 2001, 37(Suppl 4):S16S22. https://doi.org/10.1016/s0959-8049(01)00233-7 PMID: 11597400

[20] Ciardiello F, Caputo R, Bianco R, Damiano V, Fontanini G, Cuccato S, De Placido S, Bianco AR, Tortora G. Inhibition of growth factor production and angiogenesis in human cancer cells by ZD1839 (Iressa), a selective epidermal growth factor receptor tyrosine kinase inhibitor. Clin Cancer Res, 2001, 7(5):1459-1465. PMID: 11350918

[21] Brougham NDLS, Dennett ER, Cameron R, Tan ST. The incidence of metastasis from cutaneous squamous cell carcinoma and the impact of its risk factors. J Surg Oncol, 2012, 106(7):811-815. https://doi.org/10.1002/jso.23155 PMID: 22592943

[22] Mullen JT, Feng L, Xing Y, Mansfield PF, Gershenwald JE, Lee JE, Ross MI, Cormier JN. Invasive squamous cell carcinoma of the skin: defining a high-risk group. Ann Surg Oncol, 2006, 13(7):902-909. https://doi.org/10.1245/ASO.2006.07.022 PMID: 16788750

[23] Karia PS, Han J, Schmults CD. Cutaneous squamous cell carcinoma: estimated incidence of disease, nodal metastasis, and deaths from disease in the United States, 2012. J Am Acad Dermatol, 2013, 68(6):957-966. https://doi.org/10.1016/ j.jaad.2012.11.037 PMID: 23375456

[24] Chen IH, Liao CT, Wang HM, Huang JJ, Kang CJ, Huang SF. Using SCC antigen and CRP levels as prognostic biomarkers 
in recurrent oral cavity squamous cell carcinoma. PLoS One, 2014, 9(7):e103265. https://doi.org/10.1371/journal.pone.01 03265 PMID: 25061977 PMCID: PMC4111511

[25] Wee $P$, Wang Z. Epidermal growth factor receptor cell proliferation signaling pathways. Cancers (Basel), 2017, 9(5):E52. https://doi.org/10.3390/cancers9050052 PMID: 28513565 PMCID: PMC5447962

[26] Nogi H, Kobayashi T, Suzuki M, Tabei I, Kawase K, Toriumi Y, Fukushima $\mathrm{H}$, Uchida K. EGFR as paradoxical predictor of chemosensitivity and outcome among triple-negative breast cancer. Oncol Rep, 2009, 21(2):413-417. PMID: 19148516

[27] Kalyankrishna S, Grandis JR. Epidermal growth factor receptor biology in head and neck cancer. J Clin Oncol, 2006, 24(17): 2666-2672. https://doi.org/10.1200/JCO.2005.04.8306 PMID: 16763281

[28] Ang KK, Berkey BA, Tu X, Zhang HZ, Katz R, Hammond EH Fu KK, Milas L. Impact of epidermal growth factor receptor expression on survival and pattern of relapse in patients with advanced head and neck carcinoma. Cancer Res, 2002, 62(24):7350-7356. PMID: 12499279

[29] Sweeny L, Dean NR, Magnuson JS, Carroll WR, Helman EE, Hyde SO, Desmond RL, Rosenthal EL. EGFR expression in advanced head and neck cutaneous squamous cell carcinoma Head Neck, 2012, 34(5):681-686. https://doi.org/10.1002/hed. 21802 PMID: 21739514 PMCID: PMC3193876

[30] Shimizu T, Izumi H, Oga A, Furumoto H, Murakami T, Ofuji R, Muto M, Sasaki K. Epidermal growth factor receptor overexpression and genetic aberrations in metastatic squamouscell carcinoma of the skin. Dermatology, 2001, 202(3):203206. https://doi.org/10.1159/000051637 PMID: 11385224

[31] Maubec E, Duvillard P, Velasco V, Crickx B, Avril MF. Immunohistochemical analysis of EGFR and HER-2 in patients with metastatic squamous cell carcinoma of the skin. Anticancer Res, 2005, 25(2B):1205-1210. PMID: 15865067

[32] Ch'ng S, Low I, Ng D, Brasch H, Sullivan M, Davis P, Tan ST. Epidermal growth factor receptor: a novel biomarker for aggressive head and neck cutaneous squamous cell carcinoma. Hum Pathol, 2008, 39(3):344-349. https://doi.org/10.1016/j. humpath.2007.07.004 PMID: 18045646

[33] Rajeswari MRC, Saraswathi TR. Expression of epithelial growth factor receptor in oral epithelial dysplastic lesions. J Oral Maxillofac Pathol, 2012, 16(2):183-188. https://doi.org/10.4103/ 0973-029X.98496 PMID: 22923888 PMCID: PMC3424932

[34] Einama T, Ueda S, Tsuda H, Ogasawara K, Hatsuse K, Matsubara $\mathrm{O}$, Todo S, Yamamoto J. Membranous and cytoplasmic expression of epidermal growth factor receptor in metastatic pancreatic ductal adenocarcinoma. Exp Ther Med, 2012, 3(6):931-936. https://doi.org/10.3892/etm.2012.518 PMID: 22969995 PMCID: PMC3438636

[35] Bejar C, Maubec E. Therapy of advanced squamous cell carcinoma of the skin. Curr Treat Options Oncol, 2014, 15(2): 302-320. https://doi.org/10.1007/s11864-014-0280-x PMID: 24643778

[36] Maubec E, Petrow P, Scheer-Senyarich I, Duvillard P, Lacroix L, Gelly J, Certain A, Duval X, Crickx B, Buffard V, Basset-
Seguin N, Saez P, Duval-Modeste AB, Adamski H, Mansard S, Grange $F$, Dompmartin A, Faivre $S$, Mentré $F$, Avril MF. Phase II study of Cetuximab as first-line single-drug therapy in patients with unresectable squamous cell carcinoma of the skin. J Clin Oncol, 2011, 29(25):3419-3426. https://doi.org/ 10.1200/JCO.2010.34.1735 PMID: 21810686

[37] Gold KA, Kies MS, William WN Jr, Johnson FM, Lee JJ, Glisson BS. Erlotinib in the treatment of recurrent or metastatic cutaneous squamous cell carcinoma: a single-arm Phase 2 clinical trial. Cancer, 2018, 124(10):2169-2217. https://doi.org/ 10.1002/cncr.31346 PMID: 29579331 PMCID: PMC5935588

[38] William WN Jr, Feng L, Ferrarotto R, Ginsberg L, Kies M, Lippman S, Glisson B, Kim ES. Gefitinib for patients with incurable cutaneous squamous cell carcinoma: a single-arm Phase II clinical trial. J Am Acad Dermatol, 2017, 77(6): 1110-1113.e2. https://doi.org/10.1016/j.jaad.2017.07.048 PMID: 28964539 PMCID: PMC5685879

[39] Wadlow RC, Ryan DP. The role of targeted agents in preoperative chemoradiation for rectal cancer. Cancer, 2010, 116(15):3537-3548. https://doi.org/10.1002/cncr.25155 PMID: 20564106

[40] Calu V, Toma EA, Enciu O, Miron A. Clostridium difficile infection and colorectal surgery: is there any risk? Medicina (Kaunas), 2019, 55(10):683. https://doi.org/10.3390/medicina 55100683 PMID: 31658780 PMCID: PMC6843427

[41] Miron A, Giulea C, Nadragea M, Enciu O. The laparoscopic approach of small bowel obstruction - the experience of a primary center. Chirurgia (Bucharest), 2016, 111(2):126-130. PMID: 27172525

[42] Giulea C, Enciu O, Toma EA, Martin S, Fica S, Miron A. Total thyroidectomy for malignancy - is central neck dissection a risk factor for recurrent nerve injury and postoperative hypocalcemia? A tertiary center experience in Romania. Acta Endocrinol (Bucharest), 2019, 5(1):80-85. https://doi.org/10. 4183/aeb.2019.80 PMID: 31149064 PMCID: PMC6535328

[43] Nitipir C, Barbu MA, Popa LG, Mihai MM, Radu I, Mirea D, Giurcaneanu C, Scăunaşu RV. Management of papulo-pustular rash induced by epidermal growth factor receptor inhibitors. Farmacia, 2015, 63(6):805-810. https://farmaciajournal.com/ wp-content/uploads/2015-06-art-03-Nitipir 805-810.pdf

[44] Stoica C, Giurcaneanu C, Nitipir C, Popa $L \bar{G}$, Ghiordanescu I, Barbu MA, Beiu C, Ghita IA, Mihai MM. Quality of life in patients with dermatologic adverse reactions to novel antineoplastic therapy. DermatoVenerol (Bucharest), 2019, 64(3):153-166. https://revistasrd.ro/includes/files/articles/03 EN_calitatea_vietii_la_pacientii_cu_reactii_adverse_dermat ologice_la_terapii_antineoplazice_de_noua_generatie_en_ 373.pdf

[45] Li Y, Du Y, Liang X, Sun T, Xue H, Tian J, Jin Z. EGFR-targeted liposomal nanohybrid cerasomes: theranostic function and immune checkpoint inhibition in a mouse model of colorectal cancer. Nanoscale, 2018, 10(35):16738-16749. https://doi.org/ 10.1039/c8nr05803b PMID: 30156250

\section{Corresponding author}

Mara Mădălina Mihai, Assistant Professor, MD, PhD, Department of Oncological Dermatology, Elias Emergency University Hospital; Department of Dermatology, Carol Davila University of Medicine and Pharmacy, 17 Mărăşti Avenue, Sector 1, 011461 Bucharest, Romania; Phone +4021-316 16 00, e-mail: mara.mihai@umfcd.ro 